\title{
ISSUES IN IT SERVICE-ORIENTED REQUIREMENTS ENGINEERING
}

\author{
Sharman Lichtenstein \\ sharman.lichtenstein@deakin.edu.au \\ Lemai Nguyen \\ lemai.nguyen@deakin.edu.au \\ Alexia Hunter \\ alexia h@bigpond.net.au \\ School of Information Systems, Faculty of Business and Law \\ Deakin University, \\ 221 Burwood Highway, Burwood, Australia 3125
}

\begin{abstract}
Corporate information technology (IT) management is increasingly service-oriented, offering continuous evaluation and improvement of application, communication, delivery and support services to internal and external customers. Service-oriented requirements engineering (SoRE) plays a significant role in identifying and specifying service requirements, formally defined through service-level agreements (SLAs). However, the new frameworks and approaches emerging to guide these developments have not yet addressed how requirements for such services can be effectively developed, nor identified the diverse issues involved. We report a case study of a web services team development of requirements for an internal Service Desk service. The study revealed five main issues of concern when developing service provider requirements: service roles, responsibilities and accountability; service performance metrics; resolution of conflicting stakeholder service requirements; customer acceptance of service change; and service provider team structure. This study suggests that in the new IT services era, new techniques and approaches are needed for eliciting and determining provider and customer requirements that involve key stakeholder groups equitably and more closely negotiate the sometimes-conflicting provider and customer needs.
\end{abstract}

Keywords: IT service management, IT services, web services, socio-technical, requirements engineering

Acknowledgement: This paper was presented at $9^{\text {th }}$ Australian Workshop on Requirements Engineering, AWRE'04, 6-7 December, Adelaide, Australia.

\section{INTRODUCTION}

In an increasingly service-oriented economy, corporate information technology (IT) management is evolving towards service-based models that offer continuous evaluation and improvement of application, communication, delivery and support services to internal and external customers (Mayerl et al., 2000; Niessink \& Vliet, 1998; Peppard, 2003; Steen et $a l ., 2005)$. Forecasts for IT services growth are strong in the US (IDC, 2004) while slower but still positive in Australia (Hayes, 2004). Given the demand for improved IT services, there have been calls to identify approaches to developing IT service requirements, as the functionality previously offered by application software is now re-located within infrastructure (Van Eck \& Wieringa, 2003; 2004). Toward that end, this paper aims to explore issues of concern for service providers attempting to develop IT service-oriented requirements.

Requirements engineering (RE) for IT services is located within the wider context of IT service management frameworks such as IT Infrastructure Library (ITIL) and strategies that encompass people, processes, knowledge and technology within a business context (Rands, 
1992, Steen et al., 2005). Information systems strategies can also support the new IT service paradigm by aligning IT with business and reflecting a service focus (Edvardsson $e t$ al., 2000). It is within such service-focused frameworks and strategies that service requirements must be identified, and defined as service-level agreements (SLAs) and the semi-automated delivery of component-based application systems (Layzell et al., 2000; McBride, 2002).

While researchers have developed various service-oriented models and techniques to guide the development and operation of IT services (e.g. Budgen et al., 2004; Garschhammer et al., 2001; Niessink \& van Vliet, 1998; Trienekens et al., 2004), very little attention has been given to investigating the diverse issues involved in IT service requirements analysis. Illustrating the need for such research, Trienekens et al. (2004) noted recently: "There still exist many unsolved questions in the service management area, eg regarding the definition of services and the specification of SLAs" (p. 44).

Three rationale highlight the importance of an investigation of the issues involved in service-oriented RE. First, from more than 600 UK companies deploying IT services only 38 per cent had established performance metric requirements or a timeframe for future performance evaluation (Barker, 2004). Second, according to Trienekens and colleagues, service specifications can often be unclear, incomplete, negative or static (Trienekens et al., 2004)1. Third, as has traditionally been the case for systems requirements analysis, there may be significant as-yet-unexplored socio-technical issues experienced in negotiating conflicting customer and provider service requirements (Trienekens et al., 2004). Interestingly, Van Eck and Wieringa (2003) suggest that two new types of RE will emerge to complement the IT service movement: RE for service consumers (customers) and RE for service providers (providers), while Trienekens and colleagues (2004) point out the need for consensus between provider and customer in the SLA specification (Trienekens et al., 2004). Clearly, issues involved in specifying and negotiating service oriented requirements need to be explored in greater detail. Underlining an emerging interest by the RE community in the IT services sector, a workshop on Service-oriented Requirements Engineering SoRE'04 was recently held for the first time (Baresi, 2004).

In this paper, we report findings from a case study of a Web Services team engaged in developing requirements for a new service for an internal Service Desk. We contribute to the emerging area of service-oriented RE by providing new understandings of the issues involved in specifying and negotiating IT service-oriented requirements.

The paper is structured as follows. We first provide a backdrop to the empirical findings by reviewing some of the literature in IT service management. We then review existing research in service-oriented RE, suggesting that additional research is needed, and provide a socio-technical framework of service-oriented RE. The case study methodology employed is then briefly described, and the empirical results presented. Implications for theory and practice are discussed and conclusions drawn.

\section{THEORETICAL FOUNDATIONS}

In this section, we first review IT service management and demonstrate that new approaches to developing and managing services may be needed. Second, by reviewing representative approaches to the elicitation and determination of provider and customer service requirements, we highlight that this is an important but under-researched area. 


\section{IT Service Management and Guidelines}

IT service management is aimed at improving the quality of IT services and the alignment of these services with customer needs (Van Bon, 2002). It exploits existing software by offering new improved services such as performance and availability support, customer and help desk support, and education and maintenance (Trienekens et al., 2004). Experts are still deliberating the precise nature of an IT service. We embrace the following simplified definition: "An IT service is defined as a set of related functions provided by IT systems to support one or more business areas" (Mingay et al., 1998). IT service management follows an "internal vendor of services" model in which there is an increased reliance on SLAs for negotiating specific service requirements and associated budgets. The importance of SLAs is far-reaching, as they are later used to monitor whether a service is satisfactorily performed by checking aggregated performance statistics obtained from tapping web server logs, process time and other information against service performance rules in the SLA (Sailer et al., 2004).

Currently, in order to support IT Service Management, a number of service-oriented frameworks and themes have been developed. However, these guidelines lack some of the key principles, phases, and steps available in traditional systems development frameworks. In the ITIL framework, principles of project management are absent (Servicetalk, 2004) while the softer issues such as organisational culture (McBride in Servicetalk, 2004) and customer involvement are also missing. Recently, Steen and colleagues emphasised the need for interdependency between layers of environment, business, applications and technology in IT service architecture, highlighting the potential influence of socio-technical issues on IT services (Steen et al., 2005). Due to paper size constraint, IT service management is not further discussed here; however, it will be the subject of a future publication.

A further poorly addressed area in existing guidelines is the elicitation and determination of provider and customer service requirements. This is important especially - argued also by Bohmann et al. (2003) - as one of the core features of applications hosting services is heterogeneous customer requirements. This topic will be discussed in more detail in the next section.

\section{Requirements Engineering for IT Services}

In this section, we review key literature addressing the development of requirements for improved IT services. Van Eck and Wieringa (2003) assert that RE enables the specification of not only the desired IT functionality but also the services to be provided. As mentioned earlier, these authors suggest that SLAs play a central role in both types of RE: RE for service customers and RE for service providers. According to the researchers, customers will focus on identifying the tasks that need support, whereas providers will focus on achieving economies of scale such as offering a new service for multiple customers, or applying a specialised skill to a common problem. This means that providers will likely prefer to offer a standardised service which will not suit all customers. Accordingly, customers may have to adjust their processes to suit the services offered.

Trienekens et al. (2004, p. 46) suggest the need for service requirements negotiation, in that the requirements determined for the SLA must address not only customer needs, but provider needs as well: "In software management science, the importance of a consensus based approach between stakeholders (e.g. customers) and developers is emphasized 
(Boehm and Ross, 1989), in particular regarding requirements determination. These concepts, such as 'stakeholder win-win', are applicable to SLA specification, in particular to improve the usage of an SLA to serve as a communication aid and a conflict prevention instrument."

Van Eck and Wieringa (2003) point out that while requirements engineers may well ask customers what services are needed, they may also have to assist the customer in adjusting their business processes to services already provided (by providers) or to more general services suiting a wider customer base. Bohmann and colleagues highlight the key dilemma faced by the service provider as "while striving for economies of scale in service operations through standardization of services, from a customer's point of view, the service provider has to offer services which represent individual solutions that are customized to customer needs" (Bohmann et al., 2003).

In recent years, researchers have begun to develop techniques that could be employed by requirements engineers to identify service requirements specified in SLAs. We review four representative examples to illustrate the state of research in this emerging area for RE (Bohmann et al., 2003; Van Eck \& Wieringa, 2003, 2004; Niessink \& van Viet, 1998; Trienekens et al., 2004):

- Bohmann et al. (2003) argue that one of the key features of applications hosting services is the heterogeneity in customer requirements - for example, different computing platforms and communication network, the integration of different business applications and sophisticated business characteristics. The researchers introduce modular service architectures to provide standardised yet customisable IT services. The key objective is to assist service providers to address heterogeneity in customer requirements through matching and mapping required service features and factors during RE and design phases.

- Van Eck and Wieringa (2003) propose a "service blueprint" requiring the specification of key issues such as customer self-service tasks, service delivery events, generic and customer-specific services, and visibilities of sub-processes. These design decisions influence important choices such as the degree of support provided by the service provider. In a recent paper, the authors further suggest that RE might comprise the definition of required services in terms of inputs and outputs, as well as the workflow design needed to deliver the services (Van Eck \& Wieringa, 2004).

A common shortcoming in the above two approaches is their primary focus on customer requirements, while paying comparatively little heed to the very real needs of providers, who will also be affected by the new service as they may have operational roles.

- Trienekens et al. (2004) provide a phased process for specifying a SLA. In the first phase, introductions take place between an SLA expert, service provider, contract expert and customer representative. In the second phase, the customer service needs are identified. In the third phase, services are defined, qualified and metrified. During this phase there is collaboration between provider and customer during which their separate service needs are negotiated. In the fourth phase, the contract is implemented. Trienekens et al. (2004) also provide a model termed the Service Management Lemniscate which advocates an iterative cycle 
between (i) service level management that accounts for business needs and leads to defining the SLA, and (ii) service process management which involves design, implementation and monitoring. The researchers conceive IT service as under continual improvement.

- Niessink and van Vliet (1998) develop IT Service CMM as a maturity growth model - similar to the Software CMM - focusing on service process assessment and improvement. They also discuss ways to identify changed service requirements, such as analysing logged incidents, and negotiating customer requests for changed service levels or new services. Importantly, while this early maturity growth model and Trienekens et al.'s (2004) approach suggest involving both customer and provider requirements, they fail to explore this aspect in sufficient detail. Furthermore, from the perspective of an effective agreement, the negotiation of the service agreement is a critical step, and thus greater guidance is needed as to how this can be achieved.

A key weakness in the above four approaches to service-oriented RE is the absence of an in-depth consideration of the socio-technical issues involved. In traditional RE, Macaulay (1996) identified poor communication between stakeholders as the key factor limiting or enabling effective RE. Sutton (2000) and Walz et al. (1993) narrowed communication factors to three key issues: articulation, misunderstanding and conflict. As technology and systems are embedded within socio-organisational contexts and processes, strongly sociotechnical approaches to (traditional) RE are required (see for example, Mavin \& Maiden, 2003; Kotonya \& Sommerville, 1998, Goguen, 1994, 1997; Nuseibeh \& Easterbrook, 2000).

If we extrapolate and apply the above socio-technical concepts to service-oriented RE, we would expect significant stakeholder involvement in the RE process, which should develop realistic customer expectations about provider and service capabilities and needs, provide bargaining and conflict resolution between customer and provider about design issues, reduce both customer and provider resistance to change, and commit both customers and providers to the new services. According to Steen and colleagues, "a service description and a protocol of collaboration and negotiation are the only requirements for shared understanding between a service provider and a service user" (Steen et al., 2005). We suggest there are likely to be socio-technical issues which arise in service provision which must be managed. These issues will be highlighted in the case study described later. 


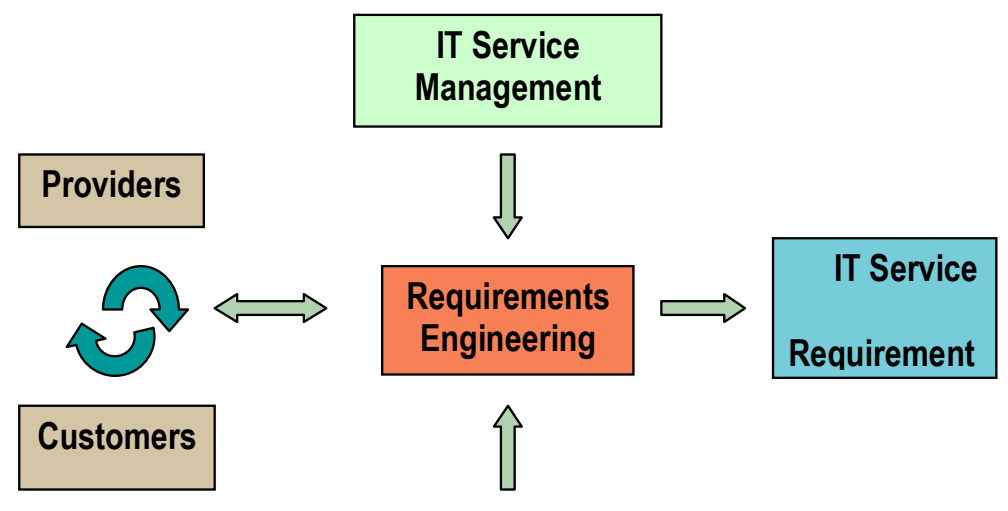

Figure 1. Service-oriented Requirements Engineering

Emerging from the literature review presented in this section is a theoretical framework to understand and study service-oriented RE (Figure 1). Within this framework, the RE process aims at producing a specification of IT service requirements (in practice, the SLA, however we have provided an abstraction). This process involves addressing both customer and provider requirements. It is guided by IT service management principles (as briefly introduced in Section 2.1) and is embedded within a socio-technical environment. Both customers and providers influence, and are influenced by, the socio-technical issues emerging in such an environment.

In the context of this framework, our study explores two key questions: What issues do service providers experience eliciting and determining IT service requirements, and how and why do these issues shape the requirements specification? This paper explores these questions by means of a case study, introduced in the next section.

\section{RESEARCH METHOD}

As part of an extensive project investigating the use of web and other technologies to support knowledge sharing (other findings are reported in Hunter, 2003; Lichtenstein et al., 2004; Lichtenstein \& Hunter, 2005), we conducted a case study based on a Web Services team in the Australian headquarters of a large multinational IT company - Glotech (real name withheld). A single case was deemed useful to explore the issues because the area of service-oriented RE is new and relatively unexplored, and a single case can yield revelatory results (Galliers, 1992).

For this paper, we focused on an analysis of issues occurring in the Web Services team's development of requirements for a planned ITIL-based web service - an adaptation of Service Desk. Service Desk solutions provide detailed business service definitions as well as a central repository to store all relations between customers, business services, SLAs and support level objectives. The planned Service Desk initiative at GloTech was aimed at improving the current processes of internal customer publication to the corporate intranet processes that, at the time, were enabled by e-mail messages between internal customers and the Web Services team. While GloTech had supplied technologies to customers for 
over a decade, the company did not yet have a procedure or approach for improving IT services or developing IT service requirements. The team comprised information systems and IT university graduates. Thus, the case study was of particular interest to our study in that it could potentially provide insights about the types of issues faced by service providers in attempting to identify IT service requirements.

The primary data collected comprised the transcript from an audio-taped two hour Web Services team meeting. During this RE meeting, the team - in the role of the service provider - collectively drafted the requirements for the new Service Desk service. Substantial secondary data were also collected from ten semi-structured audio-taped one hour interviews with Web Services team members, the corporate systems administrator and the Marketing intranet manager who was responsible for authoring and submitting marketing intranet content. The questions included an examination of the issues involved in intranet publication processes. In the interview with the Marketing manager, her concerns regarding this process were explored in depth, providing us with considerable knowledge of the Marketing customer's new service requirements. In the other interviews, many sociotechnical issues surrounding the existing intranet publication process were explored, providing additional contextual data used to enhance the primary data collected from the $\mathrm{RE}$ meeting. Meeting and interview data were supported by observations and document collection.

Coded categories and concepts discovered in the RE meeting transcript were inductively developed (Mayring, 2000) and cross-checked via a content analysis of the interview transcripts that focused on identifying issues relating to the services of internal intranet publication. Additional insights gained from observations and documents were used for additional validation and enhancement of the themes identified. In the next section, we present the findings from the study.

\section{INTERPRETATION OF RESEARCH FINDINGS}

The Web Services team comprised eight fairly young IT developers, three of whom were part-time contractors for strategic sourcing reasons. The team was headed by a full-time non-technical manager but was largely self-managing, with the manager remaining in touch with projects through weekly catch-up sessions with individual team members. The Web Services manager reported to the Australian IT Operations manager. The team's main role comprised developing, performing and maintaining web services needed by the Australian subsidiary, including a range of intranets authored by different groups.

\section{Existing Web Services intranet publication service}

At the time of study, the intranet publication service provided by the Web Services team for internal customers was co-ordinated through email messages and attachments exchanged between members of the Web Services team and the customers (although a few technical groups published directly using publishing software).

The main processes currently performed by the intranet publication services comprised:

- initial customer email request to intranet coordinator for content publication;

- assignment by intranet coordinator of the entire publication task to one of the part-time contractor Web Services team members responsible for intranet publication duties; 
- internal review of content request;

- preparation of publication proofs;

- review and approval of proofs by customer (content provider);

- live publication/update of intranet content.

A new IT service initiative had originated from a request by the Marketing intranet manager for an improved intranet publication service due to a range of concerns, discussed next.

\section{Marketing unit concerns with existing intranet publication service}

The five main concerns of Marketing with the intranet publication service - leading to a request for improved service - are summarised, following. These were reported in an indepth interview of the Marketing intranet manager conducted by the researcher.

The first key problem related to the poor turnaround performance in respect of the elapsed time between initial request for content publication and content going live. A revealing comment by the Marketing intranet manager was:

"If an article is dated the $8^{\text {th }}$ of August, then it has to be published on the intranet on the $8^{\text {th }}$, otherwise the news is old."

The second key problem was the inability to track intranet publication requests. For example, the Marketing intranet manager did not know whom to contact to find out the status of her publication requests. A related third key issue was that a single point of contact was sought for all requests.

This concern was exacerbated by the fourth key concern which was the transitory nature of the service provider team structure. Some of the Web Services team were contractors who only worked part-time, handing over intranet publication tasks to others on their weekly departure:

"I also have a problem with the handing overs of tasks by the members of the Web Services team as often requests are not completed in time and sometimes they are completed in the wrong priority. This is also a result of the Web Services contractors coming in irregularly..."

The fifth key concern was the need for flexible SLAs in publication service delivery, as some sections of the intranet required more frequent updating than others. This arrangement would enable improved scheduling by the Web Services team members and allow them to focus on the sections needing faster publication turnaround:

"Therefore I need a flexible Service Level Agreement with the Web Services team."

From analysing the problems of customers, we can see that there were five key requirements which, apart from other issues which may arise in a formal requirements analysis, should be accommodated in the planned Service Desk service. We now explore the analysis of the Web Services team meeting in which draft new Service Desk requirements were developed entirely by the team, with neither the customer nor the team manager in attendance. 


\section{Shaping of requirements by Web Services Team}

In this section, we describe how the Web Services Team inadvertently shaped new service requirements by considering their own and customers' tensions and concerns.

The Web Services team met at least once a week to report progress and make new plans. At the RE meeting, the team - without the Marketing team or team manager present - briefly discussed the various customer problems that had been reported to them at different times in phone calls made by the customer when using the email-based method of servicing intranet publishing to Marketing (and other corporate customers). The team appeared aware of the first three concerns reported in section 4.2, but not the fourth and fifth concern. Throughout the meeting, there were many reinforcements of the decision to initially meet without the customer present in order to, according to one team member, "get the story straight" before presenting draft service requirements to Marketing later. The planned initiative to resolve customer (and team) concerns consisted of designing and piloting a new Service Desk service for the Marketing customer, and later extending that service to other internal customers.

Clearly, there was a degree of tension between the Marketing customer and the Web Services team over the existing and planned service. For example, team members referred to current difficulties 'losing' customer emails - losses that had apparently been hidden from the Marketing unit. A second conflict revolved around the protracted request turnaround which the Web Services team felt the Marketing team had unfairly attributed to the Web Services team. The providers recognised the need for performance improvement, but felt that some of that improvement was needed in the content provision or reviewing stages (where they suggested the Marketing team caused delays), rather than in their own responsibilities. A third tension was the Marketing team's demand for a single point of contact, which would place the entire burden of constant availability and responsiveness on one member of the Web Services team.

Summarising, the main Web Services team's concerns with the existing publication service were:

- being held responsible, unfairly, by managers and customers for lengthy end-to-end response times;

- being unable to prove they were performing well as there was no recorded performance data;

- losing emails as there were so many incoming and outgoing for service requests and work-in-progress; and

- experiencing difficulties with tracking customer requests.

During the meeting, the team developed an initial set of requirements for an adapted Service Desk service by which the customer could submit content for publication by a web form and uploaded attachments. A draft process model was drawn on a whiteboard, augmented by a set of publication request states and various notes. Elements of design were included (e.g. web form, method of uploading attachments). The draft new service requirements model comprised the processes:

- customer submission of a request by web form and uploading of an attachment for intranet publication of content;

- opening of a ticket for the customer, internal review of proposed content by corporate intranet reviewer;

- reviewer approval; 
- return to customer for action if not approved;

- customer changes to content;

- customer approval of final version;

- live publication; and

- closing of ticket.

The team also prepared and refined a set of "compelling business reasons" to present to the Marketing customers later to help "convince" them to accept the new service requirements. The "compelling business reasons" comprised:

- $\quad$ provide a formal process for tracking publication requests;

- enable more efficient provider processing of publication requests as each request will be followed by one person from the provider team; and

- $\quad$ provide a backup system for publication requests to prevent loss.

Five key issues in eliciting and determining provider requirements - issues which clearly shaped the draft new service requirements model - were highlighted by the findings: service roles, responsibilities and accountability; service performance metrics; resolution of conflicting stakeholder service requirements; customer acceptance of service change; and service provider team structure. We discuss these issues next.

\section{Service roles, responsibilities and accountability}

Team members were very sensitive to the allocation of roles and responsibilities in the requirements, in recognition of likely ramifications for workload, accountability and performance measurement. For example:

"If they (Marketing) know it is 'pending user action' they will know it is their responsibility."

"Re-opening a ticket is very bad for a service desk. It means that the people who were handling it (Web services team) didn't do their job properly, and it reflects in the statistics."

"All I'd do (planned service queue manager) is wait on content. Instead of me (as single point of contact) being in charge of all those tasks and getting you guys to do them, you'd have your own list of tasks (as job point of contact) and basically you'd be timed on how quickly you could do them. It would free me up as a resource. I'd have my own list of tasks."

\section{Service performance metrics}

The need for the Web services team to generate good service performance statistics regardless of customer performance was a constant theme. For example:

"You guys might want to find out what kind of stats (statistics) we get (from Service Desk software), as if there is time between each comment added by the user, and three hours spent by the user on a 'pending user action', then we want that stats, not just opening and closing stats."

The proposed SLAs for publication turnaround time were discussed frequently for the same 
reason. For example:

"The proposed SLAs are 1 day for urgent requests, 3 days for normal requests, and 5 days for special requests. Nothing can be forced on us, though. They can't put everything in 1 day requests."

\section{Resolution of conflicting stakeholder service requirements}

The requirements took into account the Web services team's concerns while attempting to accommodate most known customer concerns. A constant theme was the awareness that the customer had requirements that conflicted with provider needs, or requirements that were as-yet-unknown. Team members often acted as proxies for the absent Marketing unit in order to resolve conflicts and accommodate other needs. For example, a key customer requirement was acknowledged and its omission noted with regret:

"Marketing wants a single point of contact and they won't be happy with our plan."

In many comments, the customer was perceived as potentially creating difficulties for the provider team. For example:

"If there are stats (statistics) about their content delay, that could work against their acceptance of this if they get the idea that if they don't do enough (content contribution, content review etc), they will get penalised."

"If suddenly they get measured, they are going to panic and think 'oh $<$ expletive>, we are going to have to submit stuff, and we have to do all these tickets."

However, genuine efforts were made to accommodate many perceived customer needs:

"What if they just want to find a page they've done?"

Moreover, there were frequent reminders that the customer requirements had not yet been sourced and that this still had to take place. For example:

"Keep it simple for now so they can tell us what they want and we will add that."

"Can this be changed if Marketing doesn't want it?"

It was made abundantly clear by team members - especially by the individual who would likely have to take that role - that the 'single point of contact' requested by Marketing would be too taxing for whoever had that role. Nevertheless, concern was expressed about how the customer would react to being informed that this key requirement would not be met.

Plans were also made to manage perceived risk:

"We need a Plan B for Marketing to publish with attachments (should the Service desk fail). Let them send email with attachments and a ticket number. It is easier to email with a ticket number and attachment (than use Service Desk)",

This last comment indicated uncertainty about the effectiveness of the planned Service Desk. 


\section{Customer acceptance of service change}

A major concern was how to influence the customer to accept the planned new service. There was considerable anxiety about the future need to merge as-yet-unknown customer requirements with the draft model. The change acceptance process was merged in the team's mind with eliciting and determining the customer requirements. For example:

"The whole point is to have the users accept it. One of the strategies is to find influential people in Marketing and get them onto your side. Then they can influence the rest of the group."

"If she (Marketing intranet manager) sits in on the presentation of this planned service she will feel like she was part of it."

"What are we going to call ourselves? The Pitch Team?" <laughter> "We are basically just coming up with a pitch."

\section{Service provider team structure}

The fact that the team was fairly young and included short term contractors highlighted their difficulties in relating to more senior Marketing people and negotiating their own service needs. However, this type of team is not unusual for today's IT service organisation. When discussing how to approach Marketing customers with the planned new service and convincing them to use it, it was suggested that early adopters could be approached:

"How are we going to find that out (who are the early adopters in Marketing)?"

"I can't do it as don't really know marketing all that well as I have only been here six months so I can't help."

"We can't ask the contractors to help us (do that) as they are not paid to spend time with people."

Members also expressed their concerns that they would not be heard by Marketing because they were young and the Marketing team comprised older people.

\section{DISCUSSION AND CONCLUSION}

Underpinned by a socio-technical framework in service-oriented RE (Figure 1) which emerged from a literature review, we conducted a pioneering attempt to study serviceoriented RE, helping to fill a gap in the literature and yielding important initial findings. In particular, the case study revealed five key issues of concern for service providers in service-oriented RE, which shaped the draft service requirements. The issues are: service roles, responsibilities and accountability; service performance metrics; resolution of conflicting stakeholder service requirements; customer acceptance of service change; and service provider team structure. While we cannot generalise from one case study alone, these results are indicative. Further research is needed to explore the issues identified for confirmation, validation and extension purposes. Our study also provided a new understanding of service-oriented RE in the evolving IT service management organisational 
setting.

The findings suggest three main implications for service-oriented RE in practice:

- First, businesses should recognise that although IT service provision must clearly accommodate the customer's needs, the service may have a significant impact on providers as well. If their concerns are overlooked, providers may not be fully committed to providing a quality service and may stymie service success by configuring the service requirements including performance measurement, roles and responsibilities - to compensate. Given the power represented in their technical knowledge and service configuration role, such manipulation is clearly feasible, as indeed was demonstrated in our study.

- Second, the provider concern outlined above is exacerbated by the key measure of service success - service performance. Although the provider clearly plays a role in service performance, the customer also plays a role through their responses, which can contribute to measures such as end-toend response time and other performance metrics. Therefore, the need to assign performance responsibility must be carefully and fairly handled in service-oriented RE.

- Third, the social issues have been shown to be critical to a successful service-oriented RE approach. Stakeholder groups must be able to communicate and negotiate their conflicting IT service needs. The composition of provider teams needs to be reconsidered in this light, raising new organisational issues. Experienced personnel with strong negotiation skills may be needed. Alternatively, facilitation of RE meetings can be enabled by an independent trained facilitator. Provider teams may also need training in the skills required for negotiating service requirements with customers.

Our study suggests that in the new IT services era, new techniques and approaches are needed for eliciting and determining provider and customer requirements. New methods should involve key stakeholder groups equitably and more closely negotiate the sometimesconflicting provider and customer service needs.

\section{REFERENCES}

Baresi, L. (2004) Call for papers, SoRE'04 (Service-oriented Requirements Engineering) Workshop, Japan, Available on World Wide Web at: http://serl.cs.colorado.edu/ serl/seworld/database/4128.html

Barker, D. (2004) itSMF - ITIL Best Practice: Are we Getting the Message? ServiceTalk Journal of IT Service Management Forum, 66, April, p. 3, Graeme Burn Productions, Available on World Wide Web at: http://www.itsmf.ro/downloads/april-04.pdf

Boehm, B.W. \& Ross, R. (1989) Theory-W software project management principles and examples, IEEE Transactions on Software Engineering, 15(7): pp 902-916.

Bohmann, T., Junginger, M. \& Krcmar, H. (2003) Modular Service Architectures: A concept and method for engineering IT services, Proceedings of 36th Hawaii International Conference on System Sciences (HICSS 2003), IEEE Society Press.

Budgen, D., Brereton, P. \& Turner, M. (2004) Codifying a Service Architectural Style, 
Proceedings of 28th Annual International Computer Software and Applications Conference COMPSAC 2004, Hong Kong, September 28-30.

Coughlan, J. Macredie, R. D. (2002) Effective Communication in Requirements Elicitation: A Comparison of Methodologies. Journal of Requirements Engineering, 7(2): 47-60.

Edvardsson, B., Gustafsson, A, Johnson, M. D. \& Sandén, B. (2000) New Service Development and Innovation in the New Economy, Studentlitteratur, Lund.

Galliers, R.D. (1992). Choosing Information Systems Research Approaches. In R.D. Galliers (Ed) Information Systems Research: Issues, Methods and Practical Guidelines, Blackwell Scientific Publications, Oxford, pp. 144 - 162.

Garschhammer, M., Hauck, R., Hegering, H.G., Kempter, B., Langer, M., Nerb, M., Radisic, I., Roelle, H. \& Schmidt, H. (2001) Towards Generic Service Management Concepts - A Service Model Based Approach. In G. Pavlou, N. Anerousis, and A. Liotta, Eds., Proceedings of the 7th International IFIP/IEEE Symposium on Integrated Management (IM 2001), Seattle, Washington, USA, May, IEEE Publishing.

Goguen, J. A. (1994) Requirements Engineering: Social and Technical Issues. Academic Press.

Goguen, J. A. (1997) Towards a Social, Ethical Theory of Information, In Social Science Research, Technical Systems and Cooperative Work: Beyond the Great Divide, Geoffrey Bowker, Les Gasser, Leigh Star and William Turner (Ed.), Erlbaum, pp. 2756.

Hayes, S. (2004) Services defy gloomy forecast, Australian IT News, July 24, Available on World Wide Web:

http://australianit.news.com.au/common/print $/ 0,7208,10254746 \% 5 \mathrm{e} 15317 \% 5 \mathrm{e} \% 5 \mathrm{enbv} \% 5 \mathrm{e}$ $15306,00 . \mathrm{html}$

Hunter, A. (2003) Utilisation of a Corporate Intranet for Knowledge Sharing and Retention, Unpublished Honors thesis, School of Information Systems, Deakin University, Melbourne, Australia.

IDC (2004) Worldwide Web Services Software Forecast, 2004-2008: Cautious Adoption Continues, Report \#31079, IDC. Available on World Wide Web at:

http://www.idc.com/getdoc.jsp?containerId=pr2004_04_13 090643

Kotonya, G. \& Sommerville, I. (1998) Requirements Engineering: Processes and Techniques, John Wiley and Sons.

Layzell, P., Bennett, K.H., Budgen, D., Brereton, P., Macaulay, L. \& Munro, M. (2000) Service-based Software: The Future for Flexible Software, Proceedings of Asia-Pacific Software Engineering Conference, 5-8 December, Singapore.

Lichtenstein, S., Hunter, A. \& Mustard, J. (2004) Utilisation of intranets for knowledge sharing: a socio-technical study, Proceedings of Australasian Conference on Information Systems (ACIS 2004), Tasmania, Hobart

Lichtenstein, S. \& Hunter, A. (2005) Considering the Receiver in Knowledge Sharing: When the Receiver Seems Ready the Sharer Appears, in Proceedings of 7th Australian Conference on Knowledge Management and Intelligent Decision Support (ACKMIDS 2004), Monash University, Melbourne, Australia.

Macaulay, L. A. (1996) Requirements Engineering, Springer, London.

Mavin A. \& Maiden N.A.M. (2003) Determining Socio-Technical Systems Requirements: Experiences with Generating and Walking Through Scenarios, Proceedings 11th International Conference on Requirements Engineering, IEEE Computer Society 
Press, pp. 213-222.

Mayerl, C., Nochta, Z., Muller, M., Schauer, M., Uremovic, A. \& Abeck, S. (2000) Specification of a Service Management Architecture to Run Distributed and Networked Systems, Lecture Notes In Computer Science and Proceedings of 3rd International IFIP/GI Working Conference on Trends in Distributed Systems: Towards a Universal Service Market, pp. $258-269$.

Mayring, P. (2000). Qualitative Content Analysis. Qualitative Social Research Forum, 1(2). Available on the World Wide Web at:

http://www.qualitative-research.net/fqs-texte/2-00/2-00mayring-e.htm

McBride, N. (2002) The Conceptual Development of Organisational IT Structure and Strategy with a Service Focus, Proceedings of the 7th Annual Conference of the UK Academy of Information Systems, University of Leeds, 10-12th April.

Mingay, S., Furlonger, J., Magee, F. \& Andren, E. (1998) The Five Pillars of Organizational Effectiveness, Gartner: R-06-6660.

Niessink, F. \& Vliet, H.V. (1998) Towards Mature IT Services, Software Process Improvement and Practice, June, 4(2): pp. 55-71.

Nuseibeh, B. A. and Easterbrook, S. M. (2000) Requirements Engineering: A Roadmap, In A. C. W. Finkelstein (Ed.) The Future of Software Engineering, (Companion volume to the Proceedings of the 22nd International Conference on Software Engineering, ICSE'00). IEEE Computer Society Press.

Peppard, J. (2003) Managing IT as a Portfolio of Services, European Management Journal, 21(4): pp. 467-483.

Rands, T. (1992) Information technology as a service operation, Journal of Information Technology, 7(4): pp. 189-201.

Sailer, M., Hanemann, A. \& Schmitz, D. (2004) Variety of QoS - The MNM Service Model Applied to Web Hosting Services, Proceedings of 11th Annual Workshop of HP - OVUA - HPOV 2004, HP OpenView University Association, June 20-23, Paris.

Servicetalk (2004) Servicetalk, June. Available on World Wide Web at: http://www.itsmf.be/itsmfnewsite/documenten/servicetalk/june-04.pdf

Steen, M.W.A., Strating, P., Lankhorst, M.M., ter Doest, H. \& Iacob, M.E. (2005) ServiceOriented Enterprise Architecture, in Service-Oriented Software System Engineering: Challenges and Practices, Stojanovic, Z. \& Dahanayake, A. (Eds.), IDEA Group, chapter 7.

Sutton, D. C. (2000) Linguistic problems with requirements and knowledge elicitation, Journal of Requirements Engineering, London England, 5(2): pp.114-124.

Trienekens, J.J.M., Bouman, J.J, \& van der Zwan, M. (2004) Specification of Service Level Agreements: Problems, Principles and Practices, Software Quality Journal, 12(1): pp: 43-57.

Van Bon, J. (2002) IT Service Management: An Introduction, ITSMF.

Van Eck, P. \& Wieringa, R. (2003) Requirements Engineering for Service-Oriented Computing: a Position Paper, Proceedings of First International E-Services Workshop, ICEC 03, Pittsburgh, USA, Available on World Wide Web at:

http://is.cs.utwente.nl/pubs/2003/eck wieringa icec03ws.pdf

Van Eck, P. \& Wieringa, R. (2004) Web Services as Product Experience Augmenters and the Implications for Requirements Engineering: a Position Paper, Proceedings of the International Workshop in Service-oriented Requirements Engineering, Kyoto, Japan, September 6. Available on World Wide Web at:

http://wwwhome.cs.utwente.nl/ patveck/papers/eck_wieringa_sore04_final.pdf 
Walz, D. B., Elam, J. J. \& Curtis, B. (1993) Inside a software design team: knowledge acquisition, sharing, and integration, Communication of ACM, 36(10): pp. 63-77. 